\title{
Medical treatment of colonic diverticular disease: are we sure the aim is right?
}

\author{
Gabrio Bassotti · Vincenzo Villanacci
}

Received: 27 January 2011/ Accepted: 6 March 2011 / Published online: 23 March 2011

(C) SIMI 2011

Colonic diverticular disease (DD) is one of the most common gastrointestinal conditions afflicting Western populations, with an estimated mortality in Europe of more than 20,000 per year [1]. Although most patients with DD remain asymptomatic, about one-third will develop symptoms at some point in their lives, symptoms that range from chronic mild abdominal pain to acute episodes of diverticulitis complicated by abscess or frank colonic perforation [2].

Thus, it is not surprising that, given the frequency of the condition, the therapeutic aspects are mainly devoted to try to prevent the occurrence of complications occurring in these patients, mainly the onset of diverticulitis. Among the several new therapeutic options, paralleling more traditional therapeutic approaches (dietary fibers, antibiotics, etc.) [3], the use of mesalazine has been recently proposed [4].

Why use mesalazine to treat DD? The main working hypothesis is that the chronic mucosal inflammation seen in this condition is similar to that documented in inflammatory bowel diseases $[5,6]$, and there is some evidence that mesalazine may have a role in the treatment of patients

G. Bassotti

Gastroenterology and Hepatology Section,

Department of Clinical and Experimental Medicine,

University of Perugia, Perugia, Italy

V. Villanacci

2nd Pathology Department, Spedali Civili, Brescia, Italy

G. Bassotti ( $\square)$

Clinica di Gastroenterologia ed Epatologia,

Ospedale Santa Maria della Misericordia,

Piazzale Menghini, 1, 06156 San Sisto (Perugia), Italy

e-mail: gabassot@tin.it with DD [7], due to its anti-inflammatory properties capable to reduce the number of mucosal immune cells [8].

In this issue, Gatta et al. [9] report their experience in treating uncomplicated DD with a cyclic $(800 \mathrm{mg}$ b.i.d. 10 days every month) schedule versus no treatment (control group of institutionalized elderly) during a 5-year follow-up period. During this period, $4 \%$ of treated patients and $10 \%$ of untreated patients developed diverticulitis, and, although not statistically significant, the authors conclude that mesalazine seems to be clinically effective to reduce the incidence of diverticultis in DD patients.

Apart from some study limitations (a possible beta error the study being a pilot trial, with a higher dropout of patients in the mesalazine group, design of the study using cyclical instead of continuous treatment), already recognized by the authors in the discussion, we can also suggest that the control group (elderly institutionalized subjects) was probably a suboptimal one, and the results might have been affected by the likely higher rate of other concomitant therapies in these subjects. Indeed, there is recent evidence that, at least for major complications, the concomitant use of drugs adversely affects the outcome of DD patients [10].

The main point, however, is that once again we face a study on DD that does not fully consider the full spectrum of symptoms. In fact, the symptoms taken into consideration in this study are similar to those seen in the irritable bowel syndrome, likely to overlap DD (at least in a certain percentage of patients) in this setting [11], as also shown by motility studies [12]. On the other hand, there is evidence from large patient cohorts that DD patients exhibit different and more specific abdominal pain patterns [13], and that only abdominal pain lasting for more than $24 \mathrm{~h}$ discriminates patients with DD from those with an irritable bowel syndrome (G.Bassotti, R.Cuomo, B.Annibale, unpublished data). This fact, together with the recent demonstration of 
abnormalities of both the enteric nervous system [14] and of mucosal neuropeptide pattern in symptomatic DD patients [15], suggests that the origin of symptoms may likely be due to other mechanisms than that related to low grade inflammation of the mucosa. Unfortunately, to date, no study available in the literature has taken these aspects into account.

Therefore, we feel that there is more than a fleeting possibility that the present efforts based on decreasing low grade mucosal inflammation in DD are aimed at a wrong target, i.e., decreasing irritable bowel syndrome-like symptoms [16], especially considering that notwithstanding several studies on the use of mesalazine that are available in the literature, there is still no firm documentation of such an efficacy of the drug in this setting [17].

Thus, it is our belief that only with a better understanding of the basic pathophysiological mechanisms we will be able to focus on more precise therapeutic targets, such as the identification of the pain/motility receptors responsible for the specific symptoms in these patients.

Of course, further studies carried out with accurate selection of large cohorts of patients are needed to answer these questions. In the meantime, we must rely on what we have available today, and that could (hopefully) give some relief to our patients.

Conflict of interest None.

\section{References}

1. Delvaux M (2003) Diverticular disease of the colon in Europe: epidemiology, impacton citizen health and prevention. Aliment Pharmacol Ther 18(Suppl 3):71-74

2. Hemming J, Floch M (2010) Features and management of colonic diverticular disease. Curr Gastroenterol Rep 12:399-407

3. Touzios JG, Dozois EJ (2009) Diverticulosis and acute diverticulitis. Gastroenterol Clin North Am 38:513-525

4. Floch MH, White JA (2006) Management of diverticular disease is changing. World J Gastroenterol 12:3225-3228
5. Peppercorn MA (2004) The overlap of inflammatory bowel disease and diverticular disease. J Clin Gastroenterol 38(Suppl 5):S8-S10

6. Floch MH (2006) A hypothesis: is diverticulitis a type of inflammatory bowel disease? J Clin Gastroeneterol 40(Suppl 3):S121-S125

7. Gatta L, Vakil N, Vaira D, Pilotto A, Curlo M, Comparato G, Leandro G, Ferro U, Lera M, Milletti S, Di Mario F (2010) Efficacy of 5-ASA in the treatment of colonic diverticular disease. J Clin Gastroenterol 44:113-119

8. Barbara G, Stanghellini V, Cremon C, De Giorgio R, Fronzoni L, Serra M, Corinaldesi R (2009) Aminosalicylates and other antiinflammatory compounds for irritable bowel syndrome. Dig Dis 27(Suppl 1):115-121

9. Gatta L, Di Mario F, Curlo M, Vaira D, Pilotto A, Lucarini P, Lera M, Enkleda K, Franzè A, Scarpignato C (2011) Long-term treatment with mesalazine in patients with symptomatic uncomplicated diverticular disease. Intern Emerg Med (in press)

10. Humes DJ, Fleming KM, Spiller RC, West J (2011) Concurrent drug use and the risk of perforated colonic diverticular disease: a population-based case-control study. Gut 60:219-224

11. Parra-Blanco A (2006) Colonic diverticular disease: pathophysiology and clinical picture. Digestion 73(Suppl 1):47-57

12. Bassotti G, Battaglia E, de Roberto G, Morelli A, Tonini M, Villanacci V (2005) Alterations in colonic motility and relationship to pain in colonic diverticulosis. Clin Gastroenterol Hepatol 3:248-253

13. Simpson J, Neal KR, Scholefield JH, Spiller RC (2003) Patterns of pain in diverticular disease and the influence of acute diverticulitis. Eur J Gastroenterol Hepatol 15:1005-1010

14. Bassotti G, Battaglia E, Bellone G, Dughera L, Fisogni S, Zambelli C, Morelli A, Mioli P, Emanuelli G, Villanacci V (2005) Interstitial cells of Cajal, enteric nerves, and glial cells in colonic diverticular disease. J Clin Pathol 58:973-977

15. Simpson J, Sundler F, Humes DJ, Jenkins D, Scholefield JH, Spiller RC (2009) Post inflammatory damage to the enteric nervous system in diverticular disease and its relationship to symptoms. Neuro gastroenterol Motil 21:847-858

16. Corinaldesi R, Stanghellini V, Cremon C, Gargano L, Cogliandro RF, De Giorgio R, Bartesaghi G, Canovi B, Barbara G (2009) Effect of mesalazine on mucosal immune biomarkers in irritable bowel syndrome: a randomized controlled proof-of-concept study. Aliment Pharmacol Ther 30:245-252

17. Rocco A, Compare D, Caruso F, Nardone G (2009) Treatment options for uncomplicated diverticular disease of the colon. J Clin Gastroenterol 43:803-808 